\title{
UMA ANÁLISE SOBRE A COEXISTÊNCIA DO MULTICULTURALISMO E DOS DIREITOS HUMANOS
}

Thayanne Borges Estelita

ISSUE DOI: $10.21207 / 1983.4225 .311$

\section{RESUMO}

O presente artigo tem por objetivo dialogar sobre tema aprofundado pela globalização: a universalização dos Direitos Humanos. O fim da Segunda Guerra Mundial provocou uma onda de legislações almejando à proteção de direitos básicos inerentes ao ser humano, paradigma mínimo a ser respeitado por todos os Estados. Essa tentativa de consolidar um cenário mundial saudável e protetivo não pode servir de pretexto, entretanto, para o aculturamento de Nações não abrangidas pelos valores universalmente reconhecidos e protegidos. Deve-se insistir na defesa das identidades culturais nacionais e na formação de uma política multiculturalista. Porém, o pluralismo e a estipulação unilateral de critérios mundiais são paradoxais: se cada Estado é dono e senhor de si, há possibilidade de relações internacionais hostis; se um Estado (ou organização de Estados) ergue-se como soberano regulador da matriz de valores essenciais, fatalmente ocorrerá valorização de seus próprios princípios. Ante tal embate, Habermas sugere uma teoria do discurso, na qual deve haver uma conversa justa e equilibrada entre os Estados influenciados pelo paradigma de 
direitos a ser estabelecido. Somente após esse exercício bilateral poderão ser estabelecidos Direitos Humanos ou qualquer outro ordenamento jurídico universal para os Estados de forma democrática.

Palavras-chave: Direitos Humanos. Multiculturalismo. Teoria do Discurso.

\section{INTRODUÇÃO}

Visa este trabalho a discorrer sobre um tema recente da história mundial, trazido pelo processo de globalização moderna, no fim da $2^{\mathbf{a}}$ Guerra Mundial. O avanço da humanidade trouxe algumas consequências drásticas às Nações, como o encurtamento das distâncias e a queda de barreiras, ficando prejudicadas, dessa maneira, as demarcações dos Estados, para o bem ou para o mal.

Se por um lado desenvolve-se o conceito de direitos humanos, possibilita-se a proteção ao indivíduo e cria-se um órgão para a cooperação mundial, por outro criam-se muitos paradigmas universais sem respeito ou inclusão da voz de atores mais fracos ou pequenos no cenário mundial.

Ocorre o aculturamento de Nações e se estabelece uma hierarquia de direitos mais ou menos importantes, e ainda a subjugação, controle ou enforcamento de alguns países. Tudo em nome da defesa de valores supranacionais. Como equilibrar essa balança, então? Como escolher entre a proteção de direitos humanos universais e uma comunidade multiculturalista?

Tenta-se encontrar o justo meio através da teoria do discurso, desenvolvida pelo alemão Jürgen Habermas, na qual se faz necessário um procedimento de comunicação entre os atores afetados pela matriz de valores. Somente então será possível a criação de um ordenamento positivado universal legítimo.

\section{BREVE DELIMITAÇÃO DE CONCEITOS}


Antes de discorrer sobre o conteúdo deste paper, cumpre definir algumas terminologias. É conveniente elucidar as diferenças entre multiculturalismo, pluralismo, universalismo e relativismo.

O pluralismo pode ser definido como a convivência pacífica e harmoniosa de pensamentos diferentes, sendo um fenômeno natural das sociedades livres e dos Estados Democráticos de Direito. Ele é contra, portanto, o pensamento único e vai de encontro à uma das tendências do processo de globalização. É a ideia de que não é a semelhança, ou a unanimidade, ou o consenso, e sim a diferença, o dissenso e as mudanças que contribuem para a formação da sociedade e de uma vida plena. Esse ideal é defendido pela Constituição:

Nós, representantes do povo brasileiro, reunidos em assembleia nacional constituinte para instituir um estado democrático, destinado a assegurar o exercício dos direitos sociais e individuais, a liberdade, a segurança, o bem-estar, o desenvolvimento, a igualdade e a justiça como valores supremos de uma sociedade fraterna, pluralista e sem preconceitos, fundada na harmonia social e comprometida, na ordem interna e internacional, com a solução pacífica das controvérsias, promulgamos, sob a proteção de Deus, a seguinte Constituição da República Federativa do Brasil (grifo nosso). ${ }^{196}$

Além do preâmbulo, também consta, no artigo $5^{\circ}$ da mesma Carta, o asseguramento da liberdade, de pensamento, de opinião, de culto, de associação, de ofício, de opção sexual, de casamento, de partido políti$\mathrm{co}$, dentre outras tantas garantias.

No multiculturalismo, há convivência de não apenas ideias, mas de diferentes tradições. Ele é, obviamente, pluralista, já que nele se deve abolir a uniformidade de pensamentos, tradições e culturas. Não obstante, o multiculturalismo pode ainda ser pensado de forma relativista ou de forma universalista. Na relativista, o julgamento interno é mais importante que o da sociedade internacional, ou seja, não há critérios mínimos para o diálogo entre culturas. Resumindo, tudo deve ser aceito, pois cada

196 Preâmbulo da Constituição da República Federativa do Brasil de 1988. 
cultura é livre para estabelecer seus próprios valores e direitos. Nessa abordagem, portanto, não há possibilidade de proteção internacional de direitos humanos.

Já na visão de multiculturalismo universalista é permitida a propagação de várias ideias, desde que existam valores universais básicos respeitados. Deve haver, nessa concepção, um denominador mínimo entre os atores do cenário internacional.

Dessa forma, infere-se que a defesa de direitos humanos universais é compatível com um pluralismo e multiculturalismo universalista, e inviável num ambiente multiculturalista relativista.

\section{SOBRE A UNIVERSALIDADE DOS DIREITOS HUMANOS}

Passadas essas divagações preliminares, cumpre demonstrar a evolução, a aceitação e o alcance dos direitos ditos universais.

Com a Revolução Francesa e a independência dos Estados Unidos, os direitos humanos passam pela fase da positivação, com a materialização de certos direitos naturais em textos legais situados no ápice do ordenamento jurídico dos Estados. Após essa fase histórica, os Direitos Humanos sofrem o fenômeno da generalização, cabendo aos Estados garantir a igualdade e a aplicação desses direitos na realidade social.

Concomitante ao processo de generalização, advém a internacionalização dos direitos humanos, saindo do âmbito doméstico e estatal e emergindo ao status de direitos com garantia internacional. Estabelecem-se os primeiros tratados e impõem-se limites à soberania dos Estados.

Através da adoção e aceitação da Carta das Nações Unidas, da Declaração Universal dos Direitos do Homem e de legislações internacionais posteriores no âmbito dos direitos humanos, reconheceu-se o princípio de que cada pessoa tem direito à dignidade e ao respeito, a ser reconhecida em qualquer lugar como pessoa diante da lei, assim como ninguém pode ser excluído das vantagens do direito e da justiça. Considerando que em várias socieda- 
des o direito de participar do governo e o de possuir bens foram por muito tempo privilégio e domínio exclusivo de limitadas categorias de pessoas e, em particular, em reação aos crimes contra a humanidade cometidos ao longo da Segunda Guerra Mundial, o Preâmbulo da Declaração Universal dos Direitos do Homem verificava que

O desconhecimento e o desprezo dos direitos humanos conduziram a atos de barbárie que revoltam a consciência da humanidade e que o advento de um mundo no qual os seres humanos serão livres para falar e crer, libertados do terror e da miséria, foi proclamado como a mais alta aspiração do homem. ${ }^{197}$

E sobre o alcance da Declaração, temos ainda:

Proclama a presente Declaração Universal os Direitos do Homem como um ideal comum a atingir por todos os povos e todas as nações, a fim de que todos os indivíduos e todos os órgãos da sociedade, tendo-a constantemente no espírito, se esforcem pelo ensino e pela educação, por desenvolver o respeito desses direitos e liberdades e por promover, por medidas progressivas de ordem nacional $\mathrm{e}$ internacional, o seu reconhecimento e a sua aplicação universais e efetivas, tanto entre as populações dos próprios Estados-membros como entre os povos dos territórios colocados sob sua jurisdição. ${ }^{198}$

Após esse apanhado histórico, pode-se perceber como o reconhecimento e a proteção dos Direitos Humanos são um fenômeno recente, por volta de 400 anos. Essa formulação atual tem origem direta na tradição do Ocidente, refletindo seus valores e condições sociais e econômi-

\footnotetext{
${ }^{197}$ Declaração Universal dos Direitos Humanos - DUDH. Assembleia Geral da ONU, A/Res/3/217A (10 de dezembro de 1948). Disponível em <http://www.humanrights.com/pt/what-are-human-rights/universal-declaration-of-humanrights/preamble.html>. Acessado em 15 de maio de 2015. Preâmbulo.

198 Ibidem .
} 
cas. Essa defesa, portanto, coincide com a história das sociedades ocidentais, especialmente europeias, sem qualquer menção ou interferência das experiências asiáticas, africanas, indígenas ou indianas, por exemplo. Isso demonstra o fato de que os Direitos Humanos são uma formulação de cultura ocidental e eurocêntrica, apesar de haver produção e pensamentos nesse sentido em outras partes do mundo.

Mbaya aponta ${ }^{199}$ que, já na tradição chinesa e budista, havia episódios de luta por direitos humanitários, assim como as culturas do judaísmo, cristianismo e islamismo serem impregnadas com ideias de humanidade, paz, comunidade e moral. Expõe ainda o estudioso pensamentos marxistas e oriundos do humanismo africano como defensores de um paradigma básico e universal de direitos.

Todavia, embora exista muito da ideologia ocidental na Declaração Universal, há de se reconhecer o alargamento progressivo dos direitos humanos em virtude da participação de representantes de outro sistema de pensamentos na redação dos textos fundamentais. Esse fato há de se notar pelo crescente destaque conferido aos direitos econômicos, sociais e culturais.

Dessa forma, segundo aponta Mbaya (1997), a Assembleia Geral das Nações Unidas, em 1977, esclareceu: a experiência e a contribuição do conjunto de países deverão ser levadas em consideração por todos os órgãos do sistema das Nações Unidas em suas atividades relativas aos direitos humanos e às liberdades fundamentais. É de cada um, portanto, sentir e definir tais direitos em relação às suas origens culturais e preferências filosóficas.

\section{ENFRAQUECIMENTO DA DIVERSIDADE CULTURAL}

O professor indiano R.C. Pandeya, da Universidade de Delhi, ressalta a surpresa com que os seus compatriotas encaram a perspectiva ocidental dos direitos humanos. Para um hindu, não existem direitos só pelo fato de ser humano, pois os direitos

\footnotetext{
199 MBAYA, Ethienne-Richard. Gênese, Evolução e Universalidade dos Direitos Humanos Frente à Diversidade de Culturas. Estudos Avançados, vol. 11No 30 São Paulo. Maio/agosto de 1997. Disponível em <http://www.scielo.br/scielo.php?pid=S010340141997000200003\&script=sci_arttext $>$. Acesso em 09 de abril de 2015. p. 4-5.
} 
devem ser conquistados e são resultados de obrigações. Se concedem direitos a um hindu é porque existem obrigações para esse hindu. Se há uma carta de direitos humanos, deve haver uma carta de obrigações para os seres humanos. ${ }^{200}$

O fenômeno da globalização trouxe à tona um universo de culturas às sociedades contemporâneas. Percebemos que, em Nações diferentes, direitos diferentes terão primazia, enquanto outros podem ser diminuídos e até suprimidos. Nesse cenário, a aprovação de alguns documentos pela ONU pode ser encarada com uma tomada de poder público internacional pelo ocidente. A positivação de certos direitos pelas Cartas Internacionais pós-guerra demonstra o não-reconhecimento de muitas culturas, excluídas do direito de invocar sua própria diversidade.

Barreto (2004) reforça que o problema central deste conflito insolúvel que é a relação direitos humanos e multiculturalismo é o do universalismo desses direitos sobre valores absolutos. O ilustre Norberto Bobbio, em "A Era dos Direitos", comenta que tendemos, de tanto acumular e elaborar razões e argumentos, a acreditar na ilusão de um fundamento absoluto, ou seja, um argumento irresistível, ao qual ninguém poderá recusar adesão.

O fundamento absoluto é o fundamento irresistível no mundo de nossas ideias, do mesmo modo como o poder absoluto é o poder irresistível (que se pense em Hobbes) no mundo de nossas ações. Diante do fundamento irresistível, a mente se dobra necessariamente, tal como o faz a vontade diante do poder irresistível. O fundamento último não pode mais ser questionado, assim como o poder último deve ser obedecido sem questionamentos. Quem resiste ao primeiro se põe fora da comunidade das pessoas racionais, assim como quem se rebela contra

200 REIS, Marcus Vinícius. Multiculturalismo e Direitos Humanos. Disponível em <http://www2.senado.leg.br/bdsf/item/id/70416>. Acesso em 10 de março de 2015. p.06. 
o segundo se põe fora da comunidade das pessoas justas ou boas. $^{201}$

Para basear sua argumentação segundo a qual a busca do fundamento absoluto para Direitos Humanos é ilusória, o jurista italiano aponta 4 motivos.

A primeira razão advém da própria expressão "direitos do homem". Como é notório, esse conceito é deveras vago e aberto a manipulações. "Pergunta-se, então, como é possível pôr o problema do fundamento, absoluto ou não, de direitos dos quais é impossível dar uma noção precisa", ele argumenta.

Outro motivo é que os direitos dos homens são, como facilmente pode-se observar em sua evolução, uma classe variável de direitos. Eles se modificam através da mudança das condições históricas que atravessam. Direitos que foram declarados absolutos no fim do século XVIII, como a propriedade privada, por exemplo, são submetidos a limitações nas atuais Cartas contemporâneas. Em outra via, os direitos sociais, nem mencionados no século XVIII, são altamente engrandecidos nas declarações posteriores. O que parece fundamental numa determinada época histórica e numa determinada civilização não é fundamental em outras épocas e em outras culturas:

Não se concebe como seja possível atribuir um fundamento absoluto a direitos historicamente relativos. De resto, não há por que ter medo do relativismo. A constatada pluralidade das concepções religiosas e morais é um fato histórico, também ele sujeito a modificação. $\mathrm{O}$ relativismo que deriva dessa pluralidade é também relativo. E, além do mais, é precisamente esse relativismo o mais forte argumento em favor de alguns direitos do homem, dos mais celebrados, como a liberdade de religião e, em geral, a liberdade de pensamento. Se não estivéssemos convencidos da irresistível pluralidade das concepções últimas, e se, ao contrário, estivéssemos convencidos de que asserções religiosas, éticas e políticas são demonstráveis como

201 BOBBIO, Norberto. A Era dos Direitos (edição ampliada). Trad. Carlos Nelson Coutinho. Rio de Janeiro: Campus, 1992. p. 16. 
teoremas (e essa era, mais uma vez, a ilusão dos jusnaturalistas, de um Hobbes, por exemplo, que chamava as leis naturais de "teoremas"), então os direitos à liberdade religiosa ou à liberdade de pensamento político perderiam sua razão de ser, ou , pelo menos, adquiriam um outro significado: seriam não o direito de ter a própria religião pessoal ou de expressar o próprio pensamento político, mas sim o direito de não ser dissuadido pela força de empreender a busca da única verdade religiosa e do único bem político. Reflita-se sobre a profunda diferença que existe entre o direito à liberdade religiosa e o direito à liberdade científica. $\mathrm{O}$ direito à liberdade religiosa consiste no direito de professar qualquer religião ou a não professar nenhuma. $\mathrm{O}$ direito à liberdade científica consiste não no direito de professar qualquer verdade científica ou a não professar nenhuma, mas essencialmente no direito a não sofrer empecilhos no processo da investigação científica. $^{202}$

Além de mal definida e variável, outra barreira para um fundamento absoluto em Direitos Humanos é sua heterogeneidade. A Declaração de Direitos do Homem, por exemplo, compreende pretensões muito diversas e até incompatíveis entre si. Dessa forma, os fundamentos de um determinado direito podem por vezes ser contrários aos fundamentos de outro.

A quarta e última razão apontada por Bobbio é o perigo na busca do fundamento absoluto. Ele aponta, ainda destacando a heterogeneidade dos direitos:

Pois bem: dois direitos fundamentais, mas antinômicos, não podem ter, um e outro, um fundamento absoluto, ou seja, um fundamento que o torne um direito e o seu oposto, ambos, inquestionáveis e irresistíveis. Aliás, vale a pena recordar que, historicamente, a ilusão do fundamento absoluto de alguns direitos estabelecidos foi um

202 BOBBIO, Norberto. A Era dos Direitos (edição ampliada). Trad. Carlos Nelson Coutinho. Rio de Janeiro: Campus, 1992. p. 19. 
obstáculo à introdução de novos direitos, total ou parcialmente incompatíveis com aqueles. Basta pensar nos empecilhos colocados ao progresso da legislação social pela teoria jusnaturalista do fundamento absoluto da propriedade: a oposição quase secular contra a introdução dos direitos sociais foi feita em nome do fundamento absoluto dos direitos da liberdade. O fundamento absoluto não é apenas uma ilusão; em alguns casos, é também um pretexto para defender posições conservadoras (grifo nosso). ${ }^{203}$

Barreto comenta, então, que o problema da fundamentação ética dos direitos humanos está relacionado com a busca de argumentos racionais e morais que possam embasar a pretensão da validade universal. Dessa forma, concorda com Habermas, quando conclui que o projeto de fundamentação dos direitos humanos deveria ser pensado na seara pública da sociedade democrática através de normas que expressem uma vontade política específica, consequência de um processo de argumentação racional entre seres livres.

Se a percepção dos direitos humanos está condicionada no espaço e no tempo por múltiplos fatores de ordem histórica, política, econômica, social e cultural, em virtude de tal diversidade (reflexo da própria diversidade das sociedades e concepções do homem), há de se admitir um parâmetro universal de direitos humanos? As declarações, pactos, cartas e convenções não seriam produto de condições históricas, em especial, ocidentais?

Habermas aponta duas críticas ao universalismo: uma crítica da razão e uma crítica do poder. De acordo com a primeira crítica, o tipo de racionalidade que legitima os direitos humanos universais está fatalmente comprometida com a herança cultural ocidental e com a abstração herdeira do platonismo.

Essa razão coloca-se a um "sofisma de abstração", para além dos limites do seu contexto de surgimento e, assim, para além da validade meramente local dos

${ }^{203}$ BOBBIO, Norberto. A Era dos Direitos (edição ampliada). Trad. Carlos Nelson Coutinho. Rio de Janeiro: Campus, 1992. p. 22. 
seus parâmetros, supostamente universais. Deve-se assegurar a todas as tradições, concepções de mundo ou culturas, os seus respectivos, e na verdade, incomensuráveis parâmetros para o verdadeiro e o falso. $^{204}$

Sobre a crítica de poder, o sociólogo denuncia o pretenso universalismo como uma forma de falsa neutralidade epistêmica. Aponta, então, que alguns grupos de interesses determinados escondem-se por detrás de reivindicações jurídicas universais para impor sua vontade à coletividade.

Diante do exposto, torna-se claro que a afirmação dogmática da universalidade dos critérios de valores se revela indefensável, não apenas em razão de seu caráter teórico, mas também de seu caráter prático. Quanto ao relativismo cultural sem restrição, ele tem como fim a visão de toda cultura como absoluta, não admitindo crítica sobre qualquer cultura, o que se torna também problemático na prática se uma cultura se considera responsável pelo governo e pela regulação mundial.

\section{UNIVERSALIDADE X MULTICULTURALISMO: A TEORIA DE HABERMAS}

Mediante a exposição do problema-tema deste trabalho, a questão que urge solucionar é se a universalidade dos direitos humanos pode suportar o multiculturalismo das sociedades complexas e ainda se existe ou não a possibilidade de exigir o cumprimento dos direitos humanos em todas as sociedades contemporâneas. A ideia de critérios universais já embasou atrocidades patrocinadas pelo nazismo, pelo fascismo e pelo comunismo. Se a igualdade se encontra exatamente no respeito à diferença, pode existir uma cultura global?

$\mathrm{Na}$ tentativa de solucionar essas questões, o filósofo e sociólogo alemão Jürgen Habermas propõe um procedimento discursivo visando a fundamentar racionalmente os direitos humanos através de uma teoria

204 HABERMAS, Jürgen. A Constelação Pós-Nacional: ENSAIOS POLÍTICOS. Tradução de Márcio Seligmann-Silva. São Paulo: Littera Mundi, 2001. p 152. 
discursiva desses direitos, institucionalizando-se os direitos por meio de um princípio discursivo.

Dessa forma, a matriz habermasiana buscará fundamentar direitos por meio da teoria do discurso. Essa teoria será baseada em dois princípios: o do discurso e o da democracia. Através destes princípios, podese fundamentar o sistema de direitos e garantir a autonomia privada e pública dos cidadãos, regulando uma convivência pacífica com os meios legítimos do direito positivo. Essa autonomia é muito relevante, pois há uma forte ligação entre os direitos humanos e a soberania de um povo. Assim,

A autonomia tem que ser entendida do modo mais geral e neutro. Por isso introduzi um princípio do discurso, que é indiferente em relação à moral e ao direito. Esse princípio deve assumir - pela via da institucionalização jurídica - a figura de um princípio da democracia, o qual passa a conferir força legitimadora ao processo de normatização. A ideia básica é a seguinte: o princípio da democracia resulta da interligação que existe entre o princípio do discurso e a forma jurídica. ${ }^{205}$

É por intermédio do processo democrático que os cidadãos devem chegar simetricamente ao gozo de suas liberdades subjetivas, utilizando-se de um direito legítimo que deve ser resultado da formação democrática de opinião, vontade e aceitabilidade racional do povo. Por isso, a igualdade do discurso necessita de um conjunto de direitos com vistas ao respeito da opinião e da participação de todos os envolvidos.

Sobre a possibilidade de um princípio moral universal, Araújo, comentando Habermas, aponta que

Habermas (1989) tenta comprovar a possibilidade de a razão servir de instrumento legítimo para discutir assuntos morais de modo a compreender os argumentos morais e a permitir que estes possam levantar pretensões de validade justificáveis segundo

205 HABERMAS, Jürgen. Direito e Democracia: Entre Facticidade e Validade. v. I. Tradução de Flávio Beno Siebeneichler. Rio de Janeiro: Tempo Brasileiro, 1997. p. 158. 
um princípio moral que é universal. Tenta comprovar Habermas que o cético age contra intuitivamente, uma vez que ignora as práticas comunicativas cotidianas nas quais ele mesmo sempre se insere em discursos morais utilizando-se de uma racionalidade voltada ao entendimento mútuo, onde argumenta pela validade de suas assertivas com recurso das boas razões. ${ }^{206}$

Esse princípio de universalização não pode ter formação monológica (e sim cooperação discursiva), já que argumentações reais são, por definição, argumentações entre diversos participantes e de todos os atingidos pela decisão moral em questão. A necessidade de argumentação real, portanto, é condição sine qua non para a reflexividade do processo, permitindo um consenso mútuo e intersubjetivo, evitando as distorções da perspectiva monológica.

A busca de critérios comuns a todas as culturas para a formulação de um referencial universal para as legislações requer ética dialógica. A democracia, portanto, deve ser vista como uma comunidade real de comunicação, palco da fala, fazendo com que a sociedade e o próprio sujeito não se constituam pela subjetividade ou objetividade, e sim pela intersubjetividade, produzindo teoria jurídica pela interação argumentativa.

Os princípios morais universais referidos por Habermas então servirão de legitimação do direito através do princípio da democracia, da soberania popular de uma coletividade e da autocompreensão da Nação.

\section{CONSIDERAÇÕES FINAIS}

Discorrer sobre Direitos Humanos sem repetir as mesmas obviedades não é uma tarefa fácil. Cumpre indagar a quem interessa a superproteção ora de um, ora de outro direito, em épocas específicas. A tentati-

206 ARAÚJO, Ary Salgueiro Euclides de. Ética Universal e Direitos Humanos em Habermas: Globalização e os Desafios do Multiculturalismo. In: XIX Encontro Nacional do CONPEDI, 2010, Fortaleza. Anais do Encontro, p.5657 à p.5667, disponível em: <http://www.publicadireito.com.br/conpedi/manaus/arquivos/anais/fortaleza/4 179.pdf> . Acessado em 15 de março de 2015. 
va de consolidar uma comunidade mundial saudável não pode servir de pretexto para o aniquilamento de culturas milenares e o esmagamento do espírito de uma Nação.

Não se deve, por outro lado, elevar o multiculturalismo a tal ponto de não enxergar que essa política, se extremamente relativista, pode propiciar um caos universal, de desrespeito e tratamento agressivo entre os Estados. Não se pode erguer um Estado (ou ainda uma organização de Estados) como soberano regulador da paz mundial; ainda assim, não é viável que todo Estado se julgue capaz de impor seus valores.

Uma possível solução para esse impasse é o uso da teoria do discurso de Habermas. Por meio dela, o ordenamento jurídico positivado deve ser o resultado da intersubjetividade, do diálogo equilibrado e consciente de todos os Estados afetados pela lei. Essa metodologia, portanto, apesar de exigir hercúleo esforço e debates constantes, consagra o almejado democrático de um cenário mundial ideal.

\section{REFERÊNCIAS BIBLIOGRÁFICAS}

ARAÚJO, Ary Salgueiro Euclides de. Ética Universal e Direitos Humanos em Habermas: Globalização e os Desafios do Multiculturalismo. In: XIX Encontro Nacional do CONPEDI, 2010, Fortaleza. Anais do Encontro, p.5657 à p.5667, disponível em:

<http://www.publicadireito.com.br/conpedi/manaus/arquivos/ anais/fortaleza/4179.pdf> . Acessado em 15 de março de 2015.

BARRETO, Vicente de Paulo. Multiculturalismo e Direitos Humanos:

Um Conflito Insolúvel? In: BALDI, César Augusto. (Org).

Direitos humanos na sociedade contemporânea. Rio de Janeiro: Renovar, 2004.

BOBBIO, Norberto. A Era dos Direitos (edição ampliada). Trad. Carlos Nelson Coutinho. Rio de Janeiro: Campus, 1992.

Declaração Universal dos Direitos Humanos - DUDH. Assembleia Geral da ONU, A/Res/3/217A (10 de dezembro de 1948). Disponível em <http://www.humanrights.com/pt/what-arehuman-rights/universal-declaration-of-humanrights/preamble.html>. Acessado em 15 de maio de 2015. 
HABERMAS, Jürgen. A Constelação Pós-Nacional: ENSAIOS POLÍTICOS. Tradução de Márcio Seligmann-Silva. São Paulo: Littera Mundi, 2001.

HABERMAS, Jürgen. Direito e Democracia: Entre Facticidade e Validade. v. I. Tradução de Flávio Beno Siebeneichler. Rio de Janeiro: Tempo Brasileiro, 1997.

HABERMAS, Jürgen. Consciência Moral e Agir Comunicativo. Rio de Janeiro: Tempo Brasileiro, 1989.

HAMEL, Marcio Renan. Direitos Humanos e Diversidade Cultural: O Uso Público da Razão como Categoria Necessária às Sociedades Pós-Convencionais. XXI CONPEDI, 2012, Rio de Janeiro. Anais do Congresso, disponível em: $<$ http://www.publicadireito.com.br/artigos/?cod=75455e 0629 29d32a> . Acessado em 15 de março de 2015.

MBAYA, Ethienne-Richard. Gênese, Evolução e Universalidade dos Direitos Humanos Frente à Diversidade de Culturas. Estudos Avançados, vol. 11No 30 São Paulo. Maio/agosto de 1997.

Disponível

em

<http://www.scielo.br/scielo.php?pid=S0103-

$40141997000200003 \&$ script=sci_arttext $>$. Acesso em 09 de abril de 2015.

PANDEYA, R.C. Fundamentos filosóficos de los derechos humanos. Perspectiva hindu. In Los fundamentos filosóficos de los derechos humanos. Unesco/Serbal: Barcelona, 1985, p. 299.

REIS, Marcus Vinícius. Multiculturalismo e Direitos Humanos. Disponível em <http://www2.senado.leg.br/bdsf/item/id/70416>. Acesso em 10 de março de 2015. 
